\title{
El castillo de la pureza: ¿Una historia de amor? El castillo de la pureza: A love story?
}

Recibido: 20/06/2019

Aceptado: 20/01/2020

Publicado: 26/06/2020
Virginia Medina Ávila

viky.pumasacatlan@comunidad.unam.mx https://orcid.org/0000-0002-6465-4543

Universidad Nacional Autónoma de México

Resumen: La película El castillo de la pureza, de Arturo Ripstein (1972), ${ }^{1}$ se basa en un hecho real acontecido en la Ciudad de México en 1959. El objetivo del artículo es describir el contexto del hecho, inscrito en los anales policiales de la capital mexicana y cómo una historia tan sórdida (según nuestra perspectiva) pudo ser adaptada a la pantalla como una "historia de amor", resaltándose la labor del guionista José Emilio Pacheco (JEP). Una primera lectura de la película nos muestra el encierro de una familia (obligada por el padre) y que el aislamiento del mundo exterior es aceptado por la esposa como un designio casi divino de quien ama y respeta ciegamente. Buscaremos profundizar dicha mirada ofreciendo un análisis de la información de la prensa de la época, de extractos del guion, además escenas de la película y los fotogramas correspondientes a la secuencia elegida que hemos denominado "Preámbulo de la crisis. La tranquilidad en el castillo empieza a resquebrajarse".

1. El castillo de la pureza es una producción de Estudios Churubusco y Angélica Ortiz; dirección de Arturo Ripstein; argumento y adaptación de JEP; fotografía de Alex Phillips padre, última película en la que participó; música de Joaquín Gutiérrez Heras; sonido de Jesús González Ganci. La escenografía corrió a cargo de Manuel Fontanals, quien también realizaría aquí su última intervención en el cine; ambientación de Lucero Isaac, decorados de Ernesto Carrasco, vestuario de Carlos Chávez, maquillaje de Elda Loza y edición de Rafael Castanedo (sin crédito) y Eufemio Rivera (nominal). 
Palabras clave: Cine mexicano, Filmoliteratura, Adaptación, Guión cinematográfico, José Emilio Pacheco, El castillo de la pureza, Ciudad de México, Nota policíaca.

Abstract: The movie El castillo de la pureza, by Arturo Ripstein (1972), is based on a real event that took place in Mexico City in 1959. The objective of the article is to describe the context of the event, inscribed in the police annals of the Mexican Capital and how such a sordid story (according to our perspective) could be adapted to the screen as a "love story", highlighting the work of the screenwriter José Emilio Pacheco (JEP). A first reading of the film shows us the confinement of a family (forced by the father) and that the isolation from the outside world is accepted by the wife as an almost divine plan of the one who loves and respects blindly. Our intention is to deepen this view by offering an analysis of the information from the press of the time, from excerpts from the script, as well as scenes from the film and the frames corresponding to the chosen sequence that I have named "Preamble to the crisis. The tranquility in the castle begins to crack".

Key words: Mexican cinema, Film literature, Adaptation, Screenplay, José Emilio Pacheco, El castillo de la pureza, Mexico City, Police information.

\section{Introducción}

El guion de El castillo de la pureza ${ }^{2}$ está basado en un hecho de los anales policíacos de la Ciudad de México. El argumento del filme fue robado a una autora caótica, imperfecta y a veces genial: la realidad, tal como deforma o corrige la "nota roja" de los periódicos a finales de la década de 1950. Rafael Pérez Hernández encerró a su mujer Sonia María Rosa Noé y a sus seis hijos (Indómita, 17 años; Libre, 15 años; Soberano, 14; Triunfador, 12; Bienvivir, niña de 10 años; y la recién nacida de 45 días, llamada Evolución y Pensamiento Liberal) para evitar la contaminación de la maldad del mundo exterior. La historia, fue adaptada por José Emilio Pacheco (JEP) quien hizo

2. El guion de El castillo de la pureza (1972) está localizado en el archivo de la Cineteca Nacional de México. 
una investigación minuciosa del caso, trazó el argumento y compuso el guion basado en el tema de la autoridad represiva.

México vivía los años del "desarrollo estabilizador", la migración del campo a la ciudad comenzaba a tomar dimensiones insospechadas; se creaban proyectos de ciudades satélites y colonias marginales. Finalizaban los años cincuenta, cuando una noticia impactó a la opinión pública:

Un hombre (al parecer neurótico) bajo constantes amenazas de muerte, de malos tratos, de abstinencia de cultura y comida tuvo a su esposa e hijos, durante 15 años, encerrados en una casona de La Villa, sin permitirles la convivencia humana y sin dar una explicación satisfactoria de su proceder a la policía, que le ha capturado y rescatado a sus víctimas. (Téllez, 1959, p. 40)

Bajo amenaza de matarlos, Rafael Pérez impedía a su mujer e hijos abandonar la casa, convertida en una fortaleza, la cual era también una pequeña fábrica de insecticidas, donde trabajaban todo el día. No tenían contacto con el exterior: encerraba a sus familiares en celdas cuando se portaban mal y amenazaba con matarlos, con cuchillos que traía en la bolsa, hasta que la hija mayor de 17 años (Indómita) escribió una carta donde denunció el encierro de su familia. El servicio secreto de la Policía detuvo al padre, que se definió "librepensador" y dijo que la honradez, el trabajo y la libertad eran su religión.

La historia de la familia de Rafael Pérez ocupó por varios días las ediciones periodísticas y su lectura revela el contexto de la anécdota, que adquiere trascendencia a través del proceso creativo de la adaptación para el cine, obra de JEP, quien recrea el mundo al que pertenecen los personajes, justifica la revisión hemerográfica para aprehender elementos definitorios de sus personajes y asegura el sentido de la historia y le confiere verosimilitud. Seger (2000b) escribe sobre la importancia de reconocer el contexto de los personajes de la historia, pues estos no existen en el vacío, son producto de su entorno, y "entre los contextos que más influyen a los personajes se incluye la cultura, la época histórica, la situación geográfica y la profesión” (p. 20).

Aunque del hecho sólo aparecerá la punta del iceberg en el guion, JEP recuerda el extraordinario hecho muchos años después. La investigación es un primer paso en el proceso de creación de los personajes cuando se habla de la 
adaptación de un texto periodístico a la "filmoliteratura", esto es, la relación reescritural (Pérez Bowie, 2011), dada en distintas fases: investigación del hecho periodístico-adaptación-guion-película, sobre todo cuando se quieren crear personajes protagónicos como Gabriel Lima y Beatriz del Castillo de la Pureza, inspirados en personas reales como Rafael Pérez Hernández y María Rosa Noé respectivamente. Balló (2000) nos habla de estos motivos visuales:

Si se quiere analizar y tratar los motivos visuales en el cine como instantes significantes conviene seleccionar cuántos y cuáles de estos motivos tienen suficiente entidad para iluminarnos el sentido de verificar sus huellas. No nos sirve demasiado recurrir a agrupaciones previas en el campo de la plástica. Sólo a partir de la observación y el contraste de la historia del cine podemos hacer surgir algunos motivos que establezcan una continuidad fértil a lo largo de su recorrido y que hayan encontrado un vínculo efectivo con la tradición iconográfica y las estructuras argumentales que demuestren capacidad genética, de permanente originalidad. (p. 18)

\section{Proceso de creación}

El guion fue escrito del 16 de abril al 18 de noviembre de 1971. JEP fue merecedor de dos premios Ariel (máximo galardón en la cinematografía mexicana) en 1973, por mejor argumento y mejor guion cinematográfico. Narraba la vida de una familia encerrada por el padre, en una casa ubicada en los márgenes de la ciudad:

Es la historia de una familia preservada de la historia, es decir, del tiempo social, del mundo de la calle, de la relación con todos los demás seres humanos. La historia del señor Lima, de su mujer, su hijo, sus dos hijas y de la casa: Donceles 99, detrás de cuya fachada una ilusión se materializa a lo largo de dieciocho años. La ilusión de recrear el universo, de tener un mundo enteramente propio, donde el padre de familia es el amo, el señor, el dios benéfico e indiscutible, el que establece la ley y el orden. El que dirige los destinos de sus criaturas moldeando sus sentimientos y sus ideas, reteniendo a los suyos en un limbo de perfección, en un casto paraíso de virtudes morales donde no puede filtrarse el pecado ni surgir la revuelta. (De la Colina, 1973, p. 43) 
Desde las páginas del guion asistimos al desarrollo de un caso: el de una familia que un hombre pretendió guardar pura e incontaminada, y de cómo ese mundo familiar se desintegra poco a poco, porque es imposible mantener la ilusión de preservar a los seres y a las cosas de la acción del tiempo. ¿Es posible tener un mundo al margen del mundo exterior, perfeccionar una vida al margen de la vida? Esta es la gran pregunta para crear la estructura dramática de este guion como principio unificador del filme.

El título de la película fue tomado de un ensayo de Octavio Paz sobre Marcel Duchamp, llamado precisamente Marcel Duchamp o el castillo de la pureza, cuyo final retoma un poema de Mallarmé: Le Néant parti, reste le château de la pureté ("la nada que queda, sigue siendo el castillo de la pureza" (Paz, 1968, p. 43).

La idea central (de crear una fortaleza) obedece al principio del símbolo del castillo como morada interior. El castillo es la figura del refugio interior del hombre, lugar de comunicación privilegiada de los amantes Gabriel-Beatriz. También es signo de protección, pues dentro de él se guarda algo de valor trascendente. "En la vigilia, así como en los cuentos y los sueños, el castillo está situado generalmente en las alturas o en el claro de un bosque: es una morada sólida y de difícil acceso. Es un símbolo de protección. Lo que encierra está separado del resto del mundo" (Chevalier \& Gheerbrant, 1995, pp. 261-262).

Lo que protege el castillo es la trascendencia de lo espiritual. Abriga un poder misterioso e inasequible. "El castillo simboliza el conjunto de los deseos. En el castillo, junto con el tesoro (riquezas espirituales en su aspecto eterno), la dama y el caballero constituyen la síntesis de la voluntad de salvación" (Cirlot, 1997, p. 129). La dama es el ánima: en el sentido junguiano, es Hestia, la mayor de las tres diosas vírgenes. Al contrario que Artemisa y Atenea, Hestia no se aventuraba en el mundo para explorar la naturaleza salvaje o establecerse en una ciudad, sino que permanecía dentro de la casa o del templo, contenida dentro del hogar, donde del exterior solo va a irrumpir la pertinaz lluvia.

En los 110 minutos de duración de El castillo de la pureza, se deja ver sólo la punta de una pirámide artística, sostenida por la fuerza de un guion nacido de la aventura entre la imaginación y la investigación. JEP hace lo que en teoría cinematográfica señala Seger (2000a): logra construir un "hilo dramático que conduce a un gran clímax" (p. 78): 
Las historias de la vida real nos conmueven por su valentía. Nos pueden señalar un camino, ayudándonos a conocer otras realidades. Nos pueden transmitir valores, o nos enseñan a prevenir peligros y a valorar las consecuencias de ciertas conductas. Nos pueden llevar también a mundos oscuros, educándonos acerca de la corrupción y la justicia, de la manipulación y la violencia, de tantas vidas decadentes y desperdiciadas.

JEP imagina y crea la dimensionalidad de las relaciones dinámicas para que los actores Claudio Brook (Gabriel Lima), Rita Macedo (Beatriz), Arturo Beristáin (Porvenir), Diana Bracho (Utopía) y Gladys Bermejo (Voluntad) exploren y exhiban el proceso por el cual los personajes cobren vida de manera convincente. "La mayoría de las historias con base en la historia real se centrarán en personajes convincentes" (Seger, 2000a, p. 83).

El castillo de la pureza recrea estos personajes y plasma el reconocimiento de diversos temas (que van desde la identidad familiar, integridad, comunidad, tiranía, sueño, incesto, paternalismo, represión) hasta el amor porque la anécdota es prolija. Del amor de Beatriz hacia Gabriel, podemos sostener que es una "fórmula que nos conduce a la poesía o a la alucinación delirante y sugiere un estado de inestabilidad en el que el individuo deja de ser indivisible y acepta perderse en el otro, para el otro" (Kristeva, 2013, p. 5).

La información periodística, sobre el extraño encierro de la familia de Rafael Pérez Hernández, conmovió a la opinión pública mexicana a finales de julio de 1959, lo que motivó su extensión inmediata al entonces emergente medio de la televisión. El 28 de julio, el diario La Prensa daba cuenta del interés creciente de la televisión por difundir el caso: "Hoy por la noche, en conocido programa de televisión será presentado el caso de María Rosa Noé y sus seis hijos, que se encuentran en la más espantosa miseria" (López, 1959b: p. 30). El programa televisivo mencionado era "Reina por un día", conducido por Carlos Amador y Tomás Perrín, en el canal 2 a las 20:00 horas (La Prensa, 1959, p. 25).

Cada uno de los medios recrea la anécdota. El periódico, la televisión, la novela de Luis Spota (La carcajada del gato) y el teatro con la obra de Sergio Magaña (Los motivos del lobo) atienden un hecho con personajes extraordinarios y relaciones tan conflictivas que llaman la atención de una sociedad 
que vive una época de transición: la consolidación de la política económica del "desarrollo estabilizador" y la irrupción de ciudades marginales como el nuevo rumbo de la Colonia Vallejo, en Insurgentes 1176 de la Ciudad de México, donde se hallaba la casona recreada como el castillo utópico construido por Rafael Pérez: en la película llamado Gabriel Lima, interpretado por el actor Claudio Brook.

Los personajes revelados en las notas periodísticas adquieren trascendencia. El guion alumbra el nacimiento un villano del cine mexicano: Gabriel Lima, el cínico, autoritario, dominante, pero también vulnerable, contradictorio y único por sus diálogos poéticos, y más por su concepción de la vida. El constructor de utopías en El castillo de la pureza.

\section{La trama de la película}

La historia retrata una familia dedicada a elaborar el "Raticida Veloz Vulcano 214", en una casona ruinosa en las calles del centro de la Ciudad de México, Donceles 34 (en la película será Donceles 99), donde el padre ha impuesto (durante 18 años) un régimen de vida carcelario. Gabriel Lima impone severa disciplina, castiga la más mínima falta con el aislamiento en celdas que construyó en el sótano. Nadie, salvo él, sale de la casa para comercializar el raticida.

Gabriel es un hombre de cincuenta años, ordenado y meticuloso, poseedor de ideas utópicas sobre cómo formar a su familia. Educa a sus hijos con las máximas de Goethe, Ellis, Chesterton y la lectura de las profecías de Nostradamus; se siente el "gran céltico": el "gran celta" se le llamaba a Nostradamus, el gran guerrero, el guerrero del norte (Sánchez, 2016), el "gran monarca" quien participará en la III Guerra Mundial con armas modernas y logrará la victoria... uno de los contados momentos en que parece disfrutar de la vida; además, aplica a los hijos intensos ejercicios gimnásticos.

Beatriz es la esposa leal de Gabriel: justifica el encierro, obedece y tolera humillaciones, incluso la violencia, cuando la toma de los cabellos y amenaza de matarla con una navaja. La mujer tiene cuarenta años, le gusta arreglarse con los cosméticos regalados por Gabriel, le obsesiona volver a ver el mar y juega con sus hijos a la gallina ciega, las estatuas de marfil y al coco. 
Voluntad, Porvenir y Utopía son encerrados por diversos motivos en las celdas del sótano, pero cuando Gabriel sorprende a los dos hermanos mayores en escarceo erótico, escondidos en un auto viejo que tiene en la casa, la furia se desata violentamente al golpearlos y encerrarlos, pero, sobre todo, deja en ellos una fuerte herida en su corazón. "Es malo", "está loco", dirán los hijos ya con un fuerte ánimo de rencor. Porvenir intentará revelarse, pero se topa con la celda de castigo; Utopía es acusada de coqueta, cuando el padre observa que el inspector, elemento del exterior, la acosa con la mirada. El castigo es exagerado: le corta el cabello.

A Beatriz la culpa de la situación, la cela de supuesto pasado con otros hombres, aunque con ella es la única persona con quien se siente indefenso y desprotegido; le implora perdón por sus raptos de violencia, hecho que no se verá en otro momento, ni aun cuando hace una propuesta indecorosa a una "muchachita", personaje del exterior (interpretada por María Rojo) e hija de una de las dueñas de las tlapalerías donde vende su producto, quien rechaza a Gabriel y este decide acusarla con su mamá de ser coqueta y habérsele insinuado.

Utopía es encerrada en su cuarto ante las salidas del padre, pero es ella quien se atreve a escribir y arrojar a la calle una "carta-denuncia" sobre el encierro que padecen. Aunque la llamada de auxilio no cumple su cometido por acciones del viento y de la lluvia. Gabriel es detenido por los policías mientras acudía, como en otras ocasiones, a vender su producto en la tlapalería de la mamá de la muchachita. En la casa, el "hombre de la chamarra" toca la puerta, Utopía pide a gritos desde su cuarto que le abran, mientras Beatriz y Porvenir le piden callarse. Hasta ese momento, el inspector, la penumbra grisácea y la lluvia eran los únicos elementos del exterior que habían penetrado en la casona de la familia Lima. Mientras, el hombre aquel vuelve a golpear la puerta y Utopía insiste: “Abre, ábreles". Gabriel entra a su casa (acompañado del hombre de la chamarra y el policía) y les pide esperar. Beatriz sale y dice: "Lo de el recado es mentira", algo que no entienden los intrusos.

La confusión sigue cuando Porvenir afirma, refiriéndose a su padre: "Él nos encerró, él tiene la llave". Gabriel sale de la cocina con un cuchillo que pone en el cuello de Porvenir, mientras continúan los gritos de Utopía. El hombre de la chamarra saca una pistola y se parapeta tras el coche. Gabriel ha entrado con su familia a la sala y amenaza: "Si no se largan de esta casa, mato a toda la familia". Gabriel enciende el quinqué y lo arroja al suelo, las llamas 
prenden en muebles y cortinas. El llanto de Utopía es desesperado. De pronto Beatriz se abalanza sobre Gabriel y le quita el cuchillo: cuando este intenta golpearla, se interpone Porvenir, derribando a su padre. Los hombres entran y neutralizan a Gabriel. El policía y un patrullero derriban la puerta para sacar a Utopía, quien cree falsamente que les llegó su recado. Gabriel, quien aún opone resistencia, es arrestado por los efectivos policiales. Al final, se ve a Beatriz, Porvenir, Utopía y Voluntad regresar de la comisaría a casa. Ahora la llave está en manos de la madre. Todos limpian las ruinas que dejó el incendió en la sala: están solos. Beatriz es la depositaria del legado de Gabriel.

\section{El guion y cómo se plasma en el filme}

Revisemos el guion de JEP y alternadamente la película, a fin de analizar algunos bloques dramáticos o "secuencias". Desde el inicio, en la acción preparatoria (como una idea circular) el ambiente adquiere una vitalidad dramática gracias a los ruidos y a los elementos de la puesta en escena. No hay ningún despliegue de grandes acontecimientos físicos; sin embargo, el guion expone visualmente el problema con toda sencillez y eficacia:

\section{1: Títulos}

2 a 3: Sobre un fondo negro. Se escuch a sonido de agua al caer sobre el metal.

Casi al terminar los títulos, empieza a aclararse la imagen y aparecen unas gotas de agua que en gran acercamiento resbalan sobre una superficie oxidada.

La cámara retrocede para ver una serie de latas unidas por un cordel. Llueve:

4 a 7: Interior - Patio - Día

En medio acercamiento vemos que la fila de latas cuelga de una puerta de madera.

(El sonido de las latas funciona como alarma para indicar cuando alguien abre la puerta).

La lluvia cae suavemente sobre el patio interior. Estamos en una casa ruinosa del México antiguo que en otros tiempos fue un palacio.

(Todo está siempre en penumbra, pero la luz es de gran transparencia). Cortes sucesivos:

Nos muestran el patio: hay una fuente, un árbol, helechos y otras 
plantas de sombra que le dan el aspecto sobrenatural, pero de alguna manera acogedor. Una viga apuntala el muro. Se advierten reformas a la casa, añadidos con ladrillo blanco. Dispersos en el patio, varios utensilios: una carretilla, cubetas, una escalera. Hay una pila de jaulas de pájaros, llenas de ratas.

9: Interior - Patio - Día

Sigue la llovizna que se prolongará durante toda la película. Al fondo de la casa hay un taller.

10 a 18: Interior - Taller - Día

Es el taller en que se prepara el "Raticida Veloz Vulcano 214". Se trata de un cuarto muy amplio que pudo haber sido la caballeriza de la casa y que se ha adaptado rudimentariamente para los nuevos usos. Las paredes están desnudas, manchadas por la humedad y carcomidas por el salitre. Hay una enorme mesa de tablones que alguna vez estuvo pulida y otras dos más pequeñas.

Sobre ellas y en el suelo, tapizado de serrín, se ven: latas de manteca, polvo de yeso, espátulas, desarmadores, lijas, dados, piedras de río, una loseta de mármol, un marco sin cuadro, un mortero que muele el vidrio de unos espejitos para luego mezclarlo con pinole, cacahuate, azúcar Candy. Todo da una impresión de pobreza y desorden. Sin embargo, en una esquina se advierte un canapé en buen estado. Donde quiera vemos frascos llenos de líquidos. Una lechuza disecada preside los trabajos. Los rasgos más impresionantes del taller-laboratorio son una máquina para calentar los materiales que produce un ruido intermitente, una enorme balanza con sus pesas y unas jaulas de pájaros llenas de ratas, apiladas sobre las otras en un extremo del cuarto. Las jaulas tienen piso de latón para que las ratas puedan sostenerse en pie Por la parte de atrás sella con un rudimentario dibujo de Vulcano que sostiene en vilo una rata gigante y moribunda. Enmarcan el dibujo caracteres chinos. Esta imagen, ampliada en un foto-mural deteriorado, se repite en la pared.

68 a 71: Interior - Comedor - Noche

En un cuarto casi vacío. Muebles antiguos de madera oscura, pesados. Al fondo hay un trinchador. Las paredes no tienen ningún adorno. La familia se sienta a una mesa cuadrada de un solo tablón.

72 a 76: Interior - Sala - Amanecer

Es un salón amplio, con una chimenea en desuso. En una pared con papel tapiz azuloso, hay aparatos gimnásticos pintados de amarillo 
(poleas, pesas de mano, un tablón de ejercicios, una bicicleta de adelgazar muy antigua). En la pared del costado, un mapa astronómico y una carta anatómica, enormes y vetustos. Un pizarrón de pie y una mesita con libros. Este es el sitio en que se pone GABRIEL para dar clases. Enfrente hay un sofá semicircular de cuero negro. También muy viejo. Al fondo hay una palma grande.

Al lado, una lámpara de pie con flecos y en el extremo opuesto, una mesita con una jarra y vasos y un pupitre donde se sienta PORVENIR. Al fondo, una mesa redonda con cuatro sillas y una lámpara que emplea BEATRIZ para sentarse a leerles a sus hijos.

Colgadas en la pared, dos litografías mexicanas del siglo XIX. Junto a la puerta un escritorio con una silla y una primitiva máquina "Oliver". Hay un librero en escuadra repleto de libros baratos y muy usados, frascos de alcohol que contienen arañas, lagartijas, ratones, insectos, una carabela de juguete.

Del otro lado, una pila de ropa vieja. Hay otras dos lámparas de pie, convenientemente situadas.

115: Interior - Sala - Día

BEATRIZ está limpiando los aparatos gimnásticos con una franela.

117: Interior - Cuarto GABRIEL - Día

Se acerca a su escritorio de cortina. Le quita el candado, lo abre, de un cajón saca una navaja que se guarda en la bolsa. Baja la cortina del escritorio y sale.

120 a 121: Interior - Cuarto de GABRIEL - Día

GABRIEL se levanta, va hasta la ventana, los mira chapalear [jugar] bajo la lluvia, saca su reloj de bolsillo y grita:

GABRIEL: Se acabó el descanso. Vuelvan al taller.

123 a 127: Interior - Cuarto - BEATRIZ - Día

BEATRIZ también está asomada por la ventana, viendo a sus hijos. Regresa a su tocador y vuelve a arreglarse cuidadosamente. GABRIEL entra sin tocar a la recámara.

211: Interior - Cuarto de PORVENIR - Noche

El cuarto parece muy estrecho. Casi todo lo llena una litera construida por GABRIEL. Consta de tres camas, en que, durante su primera infancia, dormían los niños. En la inferior hay un sarape que hace las veces de sobrecama y cobija. La cama está mal tendida. Entre ésta y la otra, en la trabe, hay dos cajones pintados de rojo. En la segunda cama hay una mirilla que consta de cuatro agujeros. Del otro lado hay un 
palo para evitar caídas. Metidos entre los travesaños, dos sombreros de paja y en el suelo una regadera de latón, ropa en desorden y una carretilla de madera.

212 a 213: Interior - Cuarto de UTOPÍA y VOLUNTAD - Noche

Todas estas indicaciones marcadas en el guion contienen las descripciones de lo que García Riera (1988) definió como "lo aberrante cotidiano" (p. 85) por lo que se vive en El castillo de la pureza, rutina solo alterada por un agente del exterior: la lluvia. Incluye el escenario para los encierros en las celdas del sótano. Es una cárcel establecida como tal, con reja, con un alambre de púas en el ventanuco. Lo cotidiano incluía el castigo. Si cometían alguna falta se sometían al encierro sin la menor protesta, es más, habían abolido de alguna manera el rencor.

\section{9 a 21: Interior - Sótano - Día}

En un sótano húmedo y ruinoso que tiene piso de tierra y está perpetuamente en tinieblas, GABRIEL ha construido tres celdas con ladrillos. Dos tienen puertas de barrotes y alambre de gallinero y una tiene puerta de madera con un postigo. Todas están cerradas con un candado y cadena.

275 a 276: Interior - Celdas del Sótano - Día.

UTOPÍA, VOLUNTAD Y PORVENIR ocupan cada uno su celda. Las niñas lloran.

PORVENIR que está en el calabozo de madera, contempla la oscuridad del sótano, con la mano aferrada a uno de los barrotes.

340 a 341: Interior - Celda de UTOPÍA - Día.

UTOPÍA está en una de las celdas con rejas y se cubre con una cobija. La cámara, que la ha visto desde fuera, se aleja hasta ver la puerta de la celda donde está encerrado PORVENIR.

342 a 343: Interior - Celda de PORVENIR - Día.

PORVENIR está sentado junto a la pared. También muestra huellas de la golpiza y tiene una vela prendida.

La fotografía e iluminación también son marcadas a detalle en el guion. Conforme avanza la acción cinematográfica, como hecho visual, se marcan los detalles en términos de luz y sombra. A pesar de todo lo "natural" que pueda aparecer, la luz está siempre comprendida en una elaboración estética y da relieve e impulso a la acción. 
Son precisamente todos los detalles que contiene el guion los que hacen de la película una propuesta sobre la monotonía, capturada por el veterano cinefotógrafo Alex Phillips. La fotografía de la película, como observa Paz Alicia Garciadiego (citada en García Riera, 1988), "en unos tonos más bien ocres, con una unidad fotográfica excelente ... la noche y el día siempre están en una especie de grisura (no se cambia de noche a día, se cambia de lluvia a no lluvia), a pesar de eso, no sientes para nada el agobio de la monotonía, precisamente por la riqueza del detalle" (pp. 108-109).

Al lado de los personajes (Gabriel, Beatriz, Utopía, Porvenir y Voluntad), convive un elemento que se convierte en ese personaje que llega del exterior para ambientar con su presencia y sonido al castillo: la lluvia. Aparte del inspector y los policías que irrumpirán al final, sólo la lluvia permanece como la cinta sonora de la vida de los personajes. Pertinaz o suave, se deja caer como latidos del corazón, de principio a fin, como poéticamente lo concibió JEP en el guion: "La cámara recorre lentamente los hilos a que están atadas las latas. Llega hasta ellas y describe cómo las mueve con suavidad el viento y la lluvia".

La presencia de la lluvia es lo "no prohibido" en el castillo de Gabriel Lima. Elemento lúdico del cual hablaron Emilio García Riera (1988) y el director Arturo Ripstein:

EGR: Después, los chicos mojándose también de una forma, digamos como autómatas, bajo la lluvia, como si fuera diversión natural mojarse bajo la lluvia...

$A R$ : Yo tengo la impresión de que, en esta casa, donde casi todo estaba prohibido, la lluvia no estaba prohibida, es parte de la cotidianidad. En una ciudad donde llueve prácticamente seis meses al año, la lluvia no es una prohibición; no había que evitar la lluvia, podían estar bajo ella sin que realmente les afectara en absoluto; la lluvia formaba parte de la casa.

EGR: Pero la idea que también da la escena es que se mojan en la lluvia porque es de las pocas diversiones que pueden tener y, además, una de las pocas diversiones que de todas maneras representa un contacto con lo de afuera, porque la lluvia viene de afuera.

$A R$ : La lluvia viene de afuera, sí; sus entretenimientos son meteorológicos. (p. 94) 
La pureza en el castillo permanece hasta llegar a una de las escenas que marcan un "clímax dramático": el rompimiento o desafío de las reglas en El castillo de la pureza. Es el acercamiento (francamente sexual) de los hermanos, que se produce en el auto que no se usa para nada. El auto es como una escultura, es el único adorno que hay en la casa. Es un Dodge 38, que refuerza la inmovilidad de los jóvenes hermanos que están atrapados y tan necesitados de movimiento como el auto mismo. Sin embargo (y esa es una de las paradojas), el auto está tan encerrado como ellos, y dentro del auto quedan encerrados una vez más.

\section{2 a 307: Interior - Automóvil - Noche.}

En el polvoriento interior del coche, donde hay viejas botellas de cerveza, un sombrero de mujer destruido y un rollo de alambre de gallinero, están UTOPÍA y PORVENIR en el asiento posterior.

Vemos la escena amorosa durante un momento hasta que la interrumpe un rayo de la luz lanzado por la lámpara de GABRIEL que, entre gritos, baja a golpes a sus hijos, los patea y abofetea.

\section{Personajes, relaciones y paradojas}

JEP tenía que crear (después de esbozos derivados de la investigación, experiencia e imaginación) los primeros trazos de los personajes principales, que transmitieran el tema de su historia en el guion:

GABRIEL LIMA:

9: Interior - Patio - Día.

Un hombre de 50 años, pelo abundante, rasgos endurecidos, dirige los trabajos que cada quien desempeña ...

Tiene, como es habitual, una barba de varios días.

BEATRIZ:

22 a 26: Interior - Recámara de BEATRIZ - Día.

Es una mujer de 40 años, muy hermosa.

La brevedad de las líneas del guion describe con efectividad a los personajes en su aspecto físico. El escritor construye su coherencia, añade emociones, actitudes y valores. Además, describe los detalles para lograr que personajes $\mathrm{y}$ acciones sean concretos y singulares. Incluso magnifica aspectos que pa- 
recían insignificantes en el texto periodístico, como el maltrato por jalón del pelo a los hijos: ese detalle se convertirá en un símbolo importante en la historia plasmada en el guion, donde se da una especie de "colección de cabellos" de los hijos, como si en cada mechón estuviera retratado un momento de su vida, su cambio de piel (natural o forzado) o la existencia de un auto viejo, tendrán una razón de existencia en la historia cinematográfica.

La descripción física es evocadora, porque implica otros aspectos del personaje. El escritor asocia otras cualidades, imagina detalles adicionales plasmados en el guion. Así, JEP confiere intensidad suficiente a la descripción física, de tal forma que pueda reflejarse en las interpretaciones de Claudio Brook y Rita Macedo, además de los detalles que los actores pueden utilizar en sus caracterizaciones. Incluso el azar está presente, como en el caso de la "oportuna" pancreatitis ${ }^{3}$ que sufrió Diana Bracho durante la filmación, la cual le ayudó a acentuar su aspecto lánguido y retraído. O el protocolo que Gabriel Lima (anotado en el guion desde el inicio) siempre realiza al salir de su casa, detalle que García Riera (1988) resalta: "es un hombre paranoico, obsesivo, ordenado, y también con el temor de que algo se le olvide (eso es muy curioso) cuando sale de la casa" (p. 99):

\section{1 a 42: Interior - Patio - Día.}

GABRIEL cruza el patio. Lleva en la mano una maleta. Se escucha el ruido de la máquina. Se detiene un momento, se vuelve hacia el taller. Luego revisa su llavero. Lo guarda en el bolsillo y sale. Cierra la puerta. La cámara permanece un momento sobre la puerta cerrada y las latas que se mueven todavía bajo el impulso del golpe.

Gabriel Lima construyó una casona para vivir con su familia. Tiene un cuarto privado, donde guarda sus cosas, entre ellas destaca una fotografía de su madre; se relaciona con sus hijos a través del trabajo, de la enseñanza-aprendizaje de máximas y lectura de las profecías de Nostradamus, además del castigo como acción dominante.

3. "El aparato de hacer llover era invento de Raúl Camarena, que fue uno de los dos sujetos que cayeron con pancreatitis en el curso del rodaje. La otra fue Diana Bracho; en verdad esto fue bastante horripilante, pero sirvió para darle a ella una palidez que era necesaria para el personaje" (García Riera, 1988, p. 85). 
En el mundo exterior, creó la imagen de "don Gabriel", un hombre respetable que se pone lentes; en la casa no lo hace porque considera que todo defecto físico es señal de debilidad. A su mujer la ha convertido en esa especie de princesa medieval encerrada en el torreón del castillo, mujer a quien le provee de cosméticos para que luzca hermosa, pero cela y reprime psicológica y físicamente, aunque es ella la única persona ante quien se siente frágil, vulnerable; le pedirá perdón cuando el remordimiento le genere sentimiento de culpa, pero (al mismo tiempo) la culpará de los males de la familia. En un continuo my only love, my only hate que se identifica en el sentido de Kristeva (2013):

El tema principal del texto no parece ser la iniciativa psicológica de un individuo libre ni sus impedimentos, sino el propio espacio de la pasión, el espacio amoroso. El muro, el vergel, la fuente, trazan sus fronteras y pueden ser vistos menos como fases de una experiencia psicológica que como aspectos del territorio del amor que jalona y domina un "yo" lírico. Un conflicto espacio-tiempo parece mantener en tensión el texto. (p. 257)

Gabriel entra en crisis emocional cuando bajan las ventas del raticida. Es feliz cuando escucha a Beatriz leer sobre el nacimiento del "gran céltico" (historia tomada de las profecías de Nostradamus) o es halagado por ella cuando le dice: "Tus pensamientos son extraordinarios y lo que dices es verdad". Vive con la idea de la posesión de una verdad inmutable (“¡Yo sé lo que hago!"), provocando miedo y terror. Inventa y planea construir el "castillo", trampa para cazar ratas. Pelea hasta el final e incendia su castillo cuando se ve amenazado.

JEP tiene la capacidad de situarse tras los ojos del personaje, de ver el mundo a través de su punto de vista. Responde al cómo ve el mundo Gabriel Lima, para de (alguna manera) justificar el encierro, la prisión de la familia. "Lo hago por su bien" (Téllez, 1959, p. 40), dice en las notas periodísticas el personaje real (Rafael Pérez Hernández), mientras en el guion Gabriel Lima expresa el mismo concepto, aunque a partir de una interpretación apocalíptica y recreación literario-visual: 


\section{3 a 127: Interior - Cuarto de BEATRIZ - Día.}

BEATRIZ también está asomada por la ventana, viendo a sus hijos. Regresa a su tocador y vuelve a arreglarse cuidadosamente. GABRIEL entra sin tocar a la recámara. Se detiene junto a su esposa que lo mira sin suspender su arreglo. GABRIEL mide con los ojos el espacio de la habitación.

GABRIEL: ¿Te imaginas cuántos muertos cabrían apilados en este cuarto?

Le entrega el portaviandas a BEATRIZ. Ella lo ve lleno de comida.

BEATRIZ: No comiste nada.

GABRIEL: Tengo asco. Hay millones de ratas por todas partes. Ya no se mueren. Hay que hacer raticidas más potentes. Las ratas están dejando de comerse lo que les doy. En alguna forma se avisan el peligro. BEATRIZ ha suspendido su arreglo y mira temerosa a GABRIEL, sabiendo que los exabruptos conducen a problemas mayores.

GABRIEL: Pasa una cosa, las ratas y los ratones se odian. ¿Te imaginas darles algo para que se vuelvan locos y ataquen a las ratas y se maten y se destrocen entre sí? Porque cada día nacen millones. Las hembritas recién nacidas antes de salir del nido ya están cargadas. Si estuvieran peleando o se comieran a los hijos ya no tendrían tiempo de reproducirse.

BEATRIZ lo mira como petrificada.

GABRIEL: Es el instinto. Las bestias sólo buscan el placer y reproduciéndose perpetúan su horror y asquerosidad. Es una cadena que sólo terminará con el fin de los tiempos. Y con las gentes es lo mismo. Por las ratas he aprendido a conocer a los hombres. Son iguales. Por eso no quiero que ustedes tengan ningún contacto con el mundo. Vale más que sigan encerrados aquí entre mis ratas, que ver al mejor de los que están allá afuera.

Otras facetas en la construcción de personajes y acciones a considerar son las actitudes de los protagonistas. De Beatriz hacia su esposo Gabriel Lima, por ejemplo, su actitud oscila entre el erotismo fetichista (descalza acariciando los zapatos de él) a la humillación por las violentas amenazas y vejaciones, pasando por la tímida sublevación. No obstante, hasta el final Beatriz le demostrará solidaridad y seguirá el legado de su marido: 
64 a 67: Interior - Cuarto de BEATRIZ - Día.

BEATRIZ está de pie junto a su tocador. Se da vuelta y se cubre los hombros con un chal. GABRIEL se acerca a ella y le tiende la cajita. GABRIEL: Te traigo un regalo.

BEATRIZ recibe el paquete que le da GABRIEL y lo abre entusiasmada. Es una caja llena de cosméticos.

BEATRIZ: Ven, siéntate aquí.

Se sientan los dos en el tocador. BEATRIZ le da a oler perfumes, cremas, pinturas de uñas, etc. Todo lo hace con gran entusiasmo y muy amorosamente.

BEATRIZ: Toma, huélelo; ¿te gusta?

GABRIEL: Sí.

BEATRIZ: Esta crema es buenísima para las manos. Ponte.

BEATRIZ unta la crema en las manos de GABRIEL.

BEATRIZ: A ver, déjame ponerte un poquito de esta loción.

BEATRIZ rocía de perfume el cuello y el pelo de GABRIEL, quien comienza a ponerse nervioso. Se levanta.

GABRIEL: Voy a estar abajo.

Le da la espalda y se dispone a salir. Antes de que salga, BEATRIZ se levanta, toma los domésticos y le dice:

BEATRIZ: Muchas gracias, GABRIEL.

Vuelve al tocador y empieza a arreglarse con los cosméticos que le ha traído GABRIEL.

La Beatriz de JEP encarna a la mujer que subordina su vida misma y la de sus hijos al sueño de su esposo; es el complemento del castillo, la doncella que Gabriel Lima encerró para que no se contaminara con el exterior. La mujer de la casa sonríe para distraer a Gabriel en su intento por superar los momentos de tensión, muestra de subordinación a la autoridad de Gabriel. Nunca logra impedir que sus hijos sean encerrados en las celdas del sótano. Tiene la curiosidad de guardar los cabellos de sus hijos en una cajita.

Beatriz es golpeada y humillada. Tiene miedo a Gabriel, aunque paradójicamente no miente al decir: "He sido siempre feliz contigo", en 18 años. Acostumbrada al mal trato, baja la vista. Siempre busca consolar a Gabriel. Sin embargo, hasta el final, Beatriz será fiel a los designios de Gabriel. Será ella la dueña de las llaves, de su legado. La princesa asume el control del castillo con la partida del "gran céltico": 
540 a 543: Exterior - Calle del Centro - Noche.

BEATRIZ, UTOPÍA, PORVENIR y VOLUNTAD caminan cubriéndose de la lluvia con periódicos y viendo con temor a la gente, que los mira con extrañeza.

Forman un grupo compacto y temeroso. Llegan a su casa. BEATRIZ saca la llave y abre la puerta.

544 a 545: Interior - Patio - Noche.

Suenan las latas, entran. PORVENIR cierra la puerta. Llueve suavemente en el patio. Se dirigen a la sala incendiada.

546 a 548: Interior - Sala - Noche.

UTOPÍA y PORVENIR acomodan los restos de los muebles. VOLUNTAD hace una montañita de cenizas. BEATRIZ, detrás de la palmera, ve los destrozos en la sala.

Los hijos están muy cerca de ella, como buscando su protección. La cámara se acerca a BEATRIZ que esboza una casi imperceptible sonrisa.

FIN

Las paradojas de Gabriel son la de ser un hombre dominante, así como un hombre derrotado ante Beatriz, al suplicarle perdón. Ser un hombre tirano (en el interior) y un libidinoso don Gabriel (en el exterior). Sentirse el salvador del mundo, el "gran céltico" y no ser el padre que concilie la armonía familiar. Ser un hombre obedecido indefectiblemente en su casa mediante el gesto autoritario. Sin embargo, muestra un lado afectuoso cuando emprende la búsqueda de redención. Con una leve caricia pretende apagar el enojo de su hija Utopía:

GABRIEL va hacia UTOPÍA, que con un gesto agrio está pesando los materiales y empacando. Le hace una caricia.

GABRIEL: Mi hijita, ya no estés enojada. Dime qué quieres que te traiga para que estés contenta.

UTOPÍA: No, papá, no estoy enojada.

GABRIEL: Sí, sí estás. Yo sé. Pero eres muy buena y se te va a quitar. UTOPÍA se esfuerza por sonreír. GABRIEL se aleja para verlos trabajar. 


\section{Secuencia del filme elegida para el análisis: "Preámbulo de la crisis. La tranquilidad en el castillo empieza a resquebrajarse"}

Hemos llegado al momento donde veremos los fotogramas de la secuencia elegida, así como el correspondiente fragmento del guion, donde consideramos que se logra un máximo de tensión dramática, que al mismo tiempo provoca una tensión visual, incluso poética y erótica. La secuencia elegida ha sido denominada: "Preámbulo de la crisis. La tranquilidad en el castillo empieza a resquebrajarse". ${ }^{4}$

Hasta aquí la película nos ha proporcionado toda la información acerca del contexto de la historia, los espacios donde se desarrollan las acciones, la personalidad o el carácter de los protagonistas y la cotidianidad que vive la familia en su encierro. Hemos llegado a un punto de quiebre, ya que Gabriel, el enérgico padre, está preocupado porque las ventas de su producto han disminuido y teme por su capacidad para sostener a su familia, tal y como él quisiera, y se vea mermada hasta el punto de la imposibilidad.

Vemos que la progresión dramática refleja un vuelco: empieza a cambiar la "normalidad" en el castillo. Este cambio es el que se resume en esta secuencia: la preocupación del padre y la desesperación ante la incertidumbre ("nos moriremos de hambre", dice Gabriel). Derrotado, llega al hogar donde su mujer lo espera para darle consuelo en su refugio, en su castillo medieval.

A continuación, se procede a ubicar el texto del guion con los fotogramas correspondientes, así como breves comentarios acerca de cada conjunto de imágenes. Cabe mencionar que esta secuencia (en el conjunto dramático) está casi a la mitad de la historia y es cuando vemos que el plan del padre (de mantener a su familia alejada de la maldad del mundo) comienza a desmoronarse. De ahí la denominación: "Preámbulo de la crisis. La tranquilidad en el castillo empieza a resquebrajarse", precedida por el juego de la madre y los hijos en ausencia del padre. Al momento de darse cuenta que Gabriel ha llegado, los sorprendidos vástagos dejan de jugar y corren. Beatriz guarda todo aquello que los pueda delatar y simula estar haciendo otra cosa; la observamos temerosa.

4. En el guion, va de la toma 179 a la 182. Duración dentro del filme: 1 minuto 10 segundos (inicia en el minuto 42 y termina en el minuto $43: 10$ ). 


\subsection{En el guion}

179 a 182: Interior - Patio - Anochecer.

BEATRIZ está terminando de arrojar el agua por la coladera. GABRIEL se le acerca y le ayuda. BEATRIZ sonríe con temor.

GABRIEL: Terminaremos por morirnos de hambre.

BEATRIZ: ¿Cómo?

GABRIEL: Ya nadie quiere comprarnos el producto. Dicen que les convienen más las porquerías que hacen las fábricas.

BEATRIZ: No te preocupes. El nuestro es mejor.

GABRIEL: Pues no ha de serlo si la gente ya no lo pide.

BEATRIZ: Pero Gabriel...

GABRIEL: Nos vamos a morir de hambre, te digo. Mañana mismo cortas las raciones de comida. Y en esta casa se van a usar menos los focos y todos esos lujos. Además, despídete de los cosméticos.

BEATRIZ se desespera.

BEATRIZ: ¡Pero si esos los uso para gustarte!

GABRIEL comienza a caminar por el patio.

GABRIEL: Nos vamos a morir de hambre, verás.

BEATRIZ se queda inmóvil viéndolo. GABRIEL la mira. BEATRIZ se acerca a GABRIEL y lo abraza, tratando de consolarlo.

BEATRIZ: No te pongas así. No te preocupes. Estoy segura de que no va a pasar nada.

GABRIEL la abraza también. Con la punta del zapato hace una especie de caricia en los pies descalzos de Beatriz. Se aparta, la mira. Comienza a subir las escaleras. BEATRIZ lo sigue.

\subsection{En la película}

Gabriel ha llegado al hogar. Beatriz, descalza, apura a derramar el agua que trae en la cubeta por la coladera (ver Figura 1). Gabriel, solícito, se acerca y termina la tarea de arrojar el agua (ver Figuras 2 y 3). Al finalizar los dos se muestran pensativos. Gabriel aparece preocupado. Ella está intrigada (ver Figura 4). 
Figuras 1-4

Fotogramas de secuencia "Preámbulo de la crisis..."
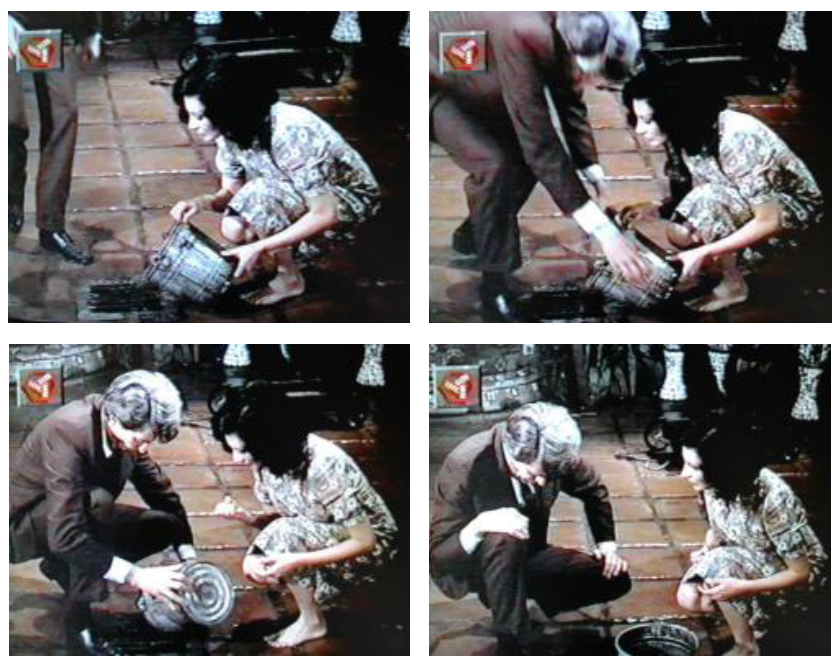

Nota: Ripstein (1972).

179 a 182: Interior - Patio - Anochecer

BEATRIZ está terminando de arrojar el agua por la coladera. GABRIEL se le acerca y le ayuda. BEATRIZ sonríe con temor.

GABRIEL: Terminaremos por morirnos de hambre.

BEATRIZ: ¿Cómo?

Figuras 5-6

Fotogramas de secuencia "Preámbulo de la crisis..."
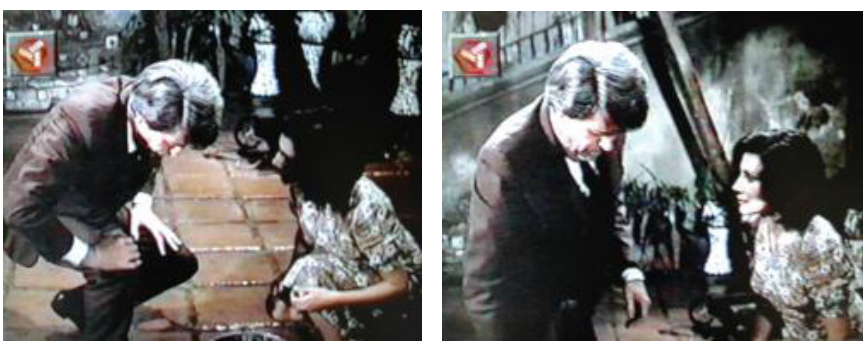

Nota: Ripstein (1972).

Gabriel exterioriza su preocupación (ver Figura 5). Beatriz no acaba de entender (ver Figura 6): 
GABRIEL: Ya nadie quiere comprarnos el producto. Dicen que les convienen más las porquerías que hacen las fábricas.

Gabriel explica la situación desesperada.

BEATRIZ: No te preocupes. El nuestro es mejor.

Beatriz, condescendiente, le da ánimos.

GABRIEL: Pues no ha de serlo si la gente ya no lo pide.

Ella lo oye y percibe cierta expresión de desconfianza que ilumina su rostro.

BEATRIZ: Pero Gabriel...

Figuras 7-9

Fotogramas de secuencia "Preámbulo de la crisis..."
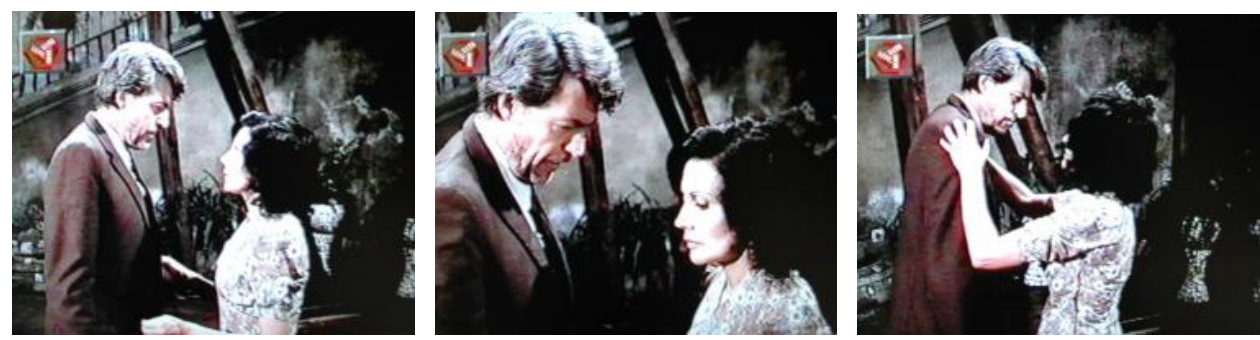

Nota: Ripstein (1972).

Beatriz lo mira fija y cariñosamente (ver Figura 7):

GABRIEL: Nos vamos a morir de hambre, te digo. Mañana mismo cortas las raciones de comida. Y en esta casa se van a usar menos los focos y todos esos lujos. Además, despídete de los cosméticos.

Gabriel no se calma. Sigue obstinado en presagiar una catástrofe. Ella lo escucha desconcertada, como quien espera lo peor (ver Figura 8):

BEATRIZ se desespera.

BEATRIZ: ¡Pero si esos los uso para gustarte!

Beatriz estoica, no desespera. Sin embargo, reacciona cuando Gabriel la amenaza con cancelarle definitivamente los cosméticos (ver Figura 9): 
GABRIEL comienza a caminar por el patio.

GABRIEL: Nos vamos a morir de hambre, verás.

Él, irritable, insiste en señalar el gran problema.

BEATRIZ se queda inmóvil viéndolo. GABRIEL la mira. BEATRIZ se acerca a GABRIEL y lo abraza, tratando de consolarlo.

BEATRIZ: No te pongas así. No te preocupes. Estoy segura de que no va a pasar nada.

Beatriz, solidaria y amorosa, conforta a Gabriel. Por fin él está calmado. Gabriel la escucha y se deja abrazar.

GABRIEL la abraza también. Con la punta del zapato hace una especie de caricia en los pies descalzos de BEATRIZ. Se aparta, la mira. Comienza a subir las escaleras. BEATRIZ lo sigue.

Las anteriores líneas del guion (plasmadas cinematográficamente) son desarrolladas de la siguiente manera. Ella asume su destino, amar a Gabriel: vemos el rito de seducción enmarcado en las caricias de Beatriz con los pies descalzos. En una suerte de sensualidad desplazada (ver Figuras 10-12); con caricias en el rostro de "su hombre", con los hijos en segundo plano que trabajan en el taller (ver Figuras 13-15); y de su humildad al consolarlo, quererlo, mimarlo y seguirlo sin ninguna condición (ver Figuras 16 y 17).

Figuras 10-17

Fotogramas de secuencia "Preámbulo de la crisis..."
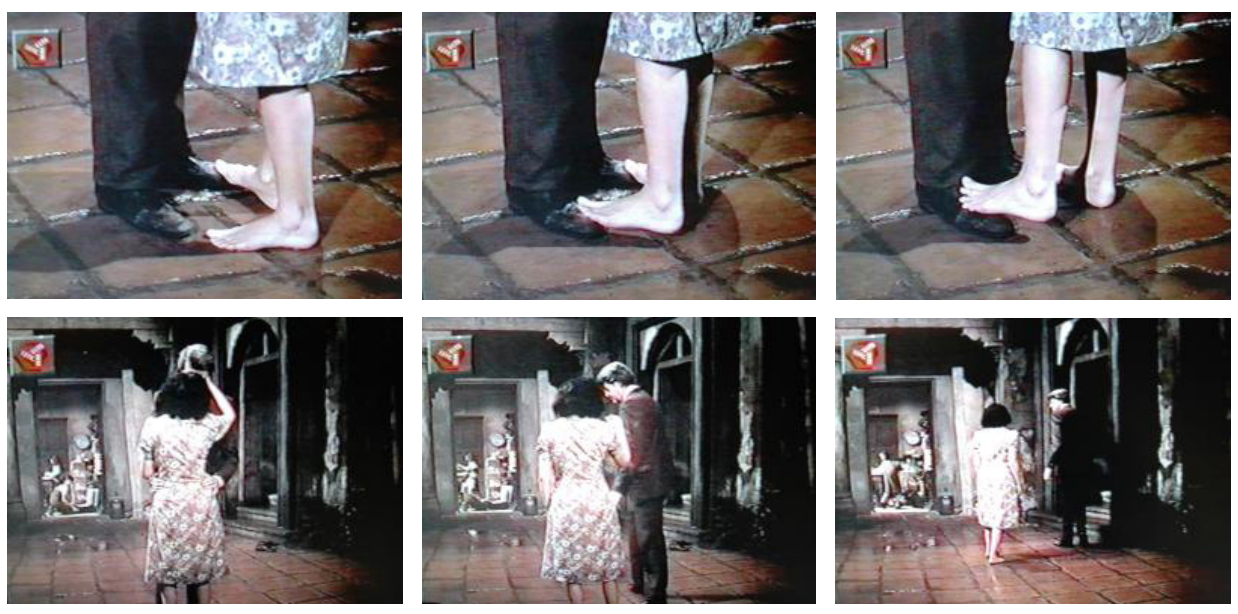

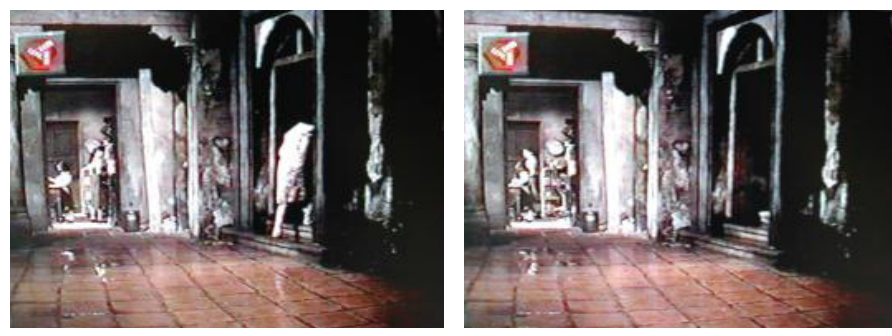

Nota: Ripstein (1972).

\section{El castillo de la pureza, ¿una historia de amor?}

Como se afirmó inicialmente, la primera lectura general de la película nos lleva hacia una historia del encierro de una familia. Sin embargo, en la secuencia seleccionada, presenciamos una historia de amor: un amor complementario, ya que Beatriz no quiere salir nunca de la casa. Vemos cómo la casa (castillo-fortaleza) es presentada como el homenaje de "amor perfecto", construido por Gabriel Lima para su dama y ella lo asume con todo amor y disposición.

Esta secuencia es precisamente una muestra de la "idea-base", la cual sirve de piedra de toque, que define a este filme como una historia del amor profesado por Beatriz a Gabriel. Describe cómo aborda Beatriz a su marido, con esa sutil iniciativa física amorosa, para seducirlo, poniendo sus pies desnudos sobre los zapatos de él: una forma de sensualidad desplazada; una especie de danza sugerida con los pies desnudos, una leve danza que adopta un sentido ritual como promesa de amor.

El sentido simbólico de esta danza ritual, llena de fuerza emotiva, se refuerza por su carácter de espectáculo minimalista, donde cada movimiento expresa un código de signos amorosos. La representación del amor a través de las caricias: una exhibición táctil. Esta escena está repleta de detalles que marcan el acercamiento sensible de la pareja, construyendo la progresión narrativa de un amor que supera las dificultades.

Se puede concluir que la toma de los pies descalzos de Beatriz, encima de los zapatos de Gabriel, es un "momento pregnante" en el sentido de Lessing (1990): "aquel que crea en el espectador la necesidad del juego libre de la fantasía” (p. 239). Esta suspensión contemplativa es la que resulta pertinen- 
te en los motivos visuales cinematográficos. Estos momentos del cine, estos segmentos de significación, son momentos de mirada que visualizan la tensión dramática, donde podemos constatar que El castillo de la pureza es una historia de amor.

\section{Fuentes consultadas}

Balló, J. (2000). Imágenes del silencio. Los motivos visuales en el cine. Anagrama.

Barthes, R. (2011). Fragmentos de un discurso amoroso. Siglo XXI.

Cirlot, J. (1997). Diccionario de símbolos. Ediciones Siruela.

Chevalier, J., \& Gheerbrant, A. (1995). Diccionario de los símbolos. Editorial Herder.

De la Colina, J. (1973). Donceles 99: El castillo asediado por el tiempo. Revista de Revistas, 32, p. 43.

García Riera, E. (1988). Arturo Ripstein habla de su cine con Emilio García Riera. Testimonios de cine, 1 .

Kristeva, J. (2013). Historias de amor. Siglo XXI.

Lessing, G. (1990). Laocoonte. Technos.

López Ortiz, A. (1959a, Julio 25). Un loco secuestró a sus familiares durante 18 años. La Prensa, 20-30.

López Ortiz, A. (1959b, Julio 28). No se salvará de la cárcel el químico secuestrador. La Prensa, 30-38.

Luna Cornea. (2013). Héctor García y su tiempo. Revista Luna Cornea, 26. https://issuu.com/c_imagen/docs/lunacornea_26 
Paz, O. (1968). Marcel Duchamp o el castillo de la pureza. Ediciones Era.

Pérez Bowie, J. (2011). Reescritura filmica: nuevos territorios de la adaptación. Universidad de Salamanca; Grupo de Estudios sobre Literatura y Cine (GELYC).

La Prensa. (1959, Julio 28). Programación de televisión, 25.

Ripstein, A. (Director). (1972). El castillo de la pureza [Film]. Estudios Churubusco, Ciudad de México.

Ronquillo, V. (1993). La esposa y los seis hijos de Rafael Pérez Hernández. En Nota roja de los 50's (p. 98). Editorial Diana.

Sánchez, M. (2016). Cronología profética de Nostradamus, 1500-1599: Vol. I. Editorial Círculo rojo.

Seger, L. (2000a). El arte de la adaptación. Cómo convertir hechos y ficciones en películas. Rialp.

Seger, L. (2000b). Cómo crear personajes inolvidables. Paidós.

Téllez, E. (1959, Julio 25). Secuestró 15 años a su esposa y seis hijos. El Universal, 40. 